\title{
A practical guide for probiotics applied to the case of antibiotic-associated diarrhea in The Netherlands
}

\author{
Valeria Agamennone ${ }^{1}$, Cyrille A. M. Krul ${ }^{1}$, Ger Rijkers ${ }^{2}$ and Remco Kort ${ }^{1,3,4^{*}}$ (D)
}

\begin{abstract}
Background: Antibiotic-associated diarrhea (AAD) is a side-effect frequently associated with the use of broad spectrum antibiotics. Although a number of clinical studies show that co-administration of specific probiotics reduces the risk for $A A D$, there is still unclarity among healthcare professionals on the recommendation of probiotic products. This paper aims at a practical guide to inform healthcare professionals, patients and consumers about the exact product characteristics of available probiotics with a proven efficacy to prevent AAD.
\end{abstract}

Methods: The workflow in this paper includes three consecutive steps: 1) systematic review of relevant clinical studies for effective probiotics by a meta-analysis, 2) compilation of a list of available probiotic products, and 3) recommendation of probiotic products that match effective formulations. Our systematic review on the efficacy of probiotics for the prevention of AAD included only studies with randomized, double blind placebo-controlled trials, a clear definition of antibiotic associated diarrhea, and a probiotic administration regime for at least the duration of the antibiotic therapy.

Results: Using our inclusion criteria, we selected 32 out of 128 identified trials and pooled the results of these studies for each specific dairy product and food supplement. The results indicate a total of seven single or multiple-strain formulations favoring the probiotic treatment group, with the strain Lactobacillus rhamnosus GG being the most effective [relative risk ratio of probiotic versus placebo 0.30 (95\% Cl 0.16-0.5) ]. We selected products for recommendation from a compiled list of all probiotic dairy products and food supplements available in The Netherlands and categorized them into groups of products showing effects against the incidence of AAD in at least one, two or three independent clinical studies. We excluded all products which did not unambiguously declare on the label the specific probiotic strain(s) and the number of colony forming units.

Conclusion: Here we present a practical guide that informs healthcare professionals and patients on the availability of probiotic products with a proven efficacy for the prevention of AAD.

Keywords: Meta-analysis, Probiotics, Antibiotics, Antibiotic-associated diarrhea (AAD)

\footnotetext{
* Correspondence: remco.kort@tno.nl

The initiative for this practical guide for probiotics in The Netherlands was presented at the annual meeting of the International Association of Prebiotics and Probiotics (ISAPP) in Singapore, June 2018.

${ }^{1}$ Microbiology and Systems Biology, Netherlands Organization for Applied Scientific Research (TNO), Utrechtseweg 48, 3704, HE, Zeist, The Netherlands ${ }^{3}$ Artis-Micropia, Plantage Kerklaan 38, 1018, CZ, Amsterdam, The Netherlands Full list of author information is available at the end of the article
}

(c) The Author(s). 2018 Open Access This article is distributed under the terms of the Creative Commons Attribution 4.0 International License (http://creativecommons.org/licenses/by/4.0/), which permits unrestricted use, distribution, and reproduction in any medium, provided you give appropriate credit to the original author(s) and the source, provide a link to the Creative Commons license, and indicate if changes were made. The Creative Commons Public Domain Dedication waiver (http://creativecommons.org/publicdomain/zero/1.0/) applies to the data made available in this article, unless otherwise stated. 


\section{Background}

\section{Antibiotic associated diarrhea (AAD)}

The use of antibiotics is associated with a variety of side-effects. The most common side effects are gastro-intestinal, such as nausea and diarrhea (Additional file 1). Antibiotic-associated diarrhea (AAD) arises when the antibiotic disrupts the ecology of the intestinal microbiota, by altering the diversity and numbers of bacteria in the gut. These changes can affect the capacity of the resident microbiota to resist the invasion of pathogenic microorganisms [1] or the overgrowth of opportunistic pathogens species that are endogenously present in the microbiota [2,3]. Even after the recovery of total bacterial counts, there can be long-lasting effects on the balance of the intestinal microbiota and consequently on the patient's susceptibility to infection and other diseases $[4,5]$. Therefore, AAD may result in prolonged hospitalization, increased health care costs and other complications. Diarrhea is most frequently associated with the use of broad spectrum antibiotics [6-8], and a tendency to an increase in the prescriptions of broad-spectrum antibiotics has been observed even in a low-prescribing country like the Netherlands (Fig. 1) [9]. For example, the broad-spectrum antibiotic amoxicillin is one of the top 25 drugs that have increased in the numbers of prescriptions in 2015 [10]. Therefore, it is important to consider the methods currently used to contrast the incidence of $\mathrm{AAD}$ and to evaluate their efficacy.

\section{Probiotics as prophylaxis}

Probiotics are "live microorganisms that, when administered in adequate amounts, confer a health benefit on the host" [11]. The core benefit of probiotics is exercised by contributing to the maintenance of a balanced microbiota and therefore by creating a favorable gut environment [12]. Furthermore, probiotics support the health of the digestive tract and the immune system [12]. The positive effect of probiotics on gut health in a variety of conditions (antibiotic-associated and infectious diarrhea, irritable bowel syndrome, necrotizing enterocolitis, etc.) has been evaluated by a number of randomized controlled clinical trials [13]. Probiotics can antagonize pathogenic microorganisms in a variety of ways. They can compete with pathogens for nutrients and adhesion sites on the gastrointestinal mucosa $[14,15]$ in the process of competitive exclusion [16]. They can also prevent pathogenicity by interfering with signaling between pathogens by degrading quorum sensing molecules [17]. In addition, direct antagonism can occur through the production of bacteriocins or metabolites with antimicrobial activity against pathogenic microorganisms $[18,19]$. Finally, probiotics are able to modulate and stimulate local and systemic immune responses in the patient [20].
According to the Agency for Healthcare Research and Quality (AHRQ) there is not enough information to confidently judge the safety of probiotic-based interventions [21]. This is because many clinical trials do not adequately document adverse events, and also because rare adverse events are difficult to assess. Still, probiotic products are generally regarded as safe, and they are used both by healthy and ill people globally. Possible safety concerns include diseases such as bacteremia and fungemia [22], and are especially concerning for patients with a weakened or compromised immune system (critically ill infants, post-surgery and hospitalized patients, immuno-compromised patients are at high risk $[23,24])$. Additionally, probiotics can constitute a source of antibiotic resistance genes. Although commercial probiotic strain are tested for the presence of such genes, reports have documented the presence of antibiotic resistance in probiotic bacteria from dietary supplements $[25,26]$.

\section{Scope of the paper}

In this paper we present a practical guide to the use of probiotics for the prevention of antibiotic-associated diarrhea. The guide is based on available scientific evidence and developed by following a workflow in three steps: 1) evaluation of the efficacy of probiotics in the context of AAD and identification of effective strains/ formulations by a systematic review of relevant clinical trials and meta-analysis of their results; 2) identification of probiotic products available to the target population; 3) recommendation of specific probiotic products matching effective formulations. The scope of this guide is to inform healthcare professionals and patients on the availability of probiotic products with a proven efficacy for the prevention of AAD.

\section{Methods \\ Search strategy and inclusion criteria}

Included in this review are studies that assessed the efficacy of probiotics in reducing the incidence of antibiotic-associated diarrhea (AAD) in patients treated with antibiotics, regardless of their age, of the intervention setting (hospital or outpatients) and of the indication for which they were prescribed. In order to identify these studies we first screened the references listed by previously published systematic reviews and meta-analyses, and then we directly searched clinical trials in public databases. Database searches were conducted on the 16th of January 2017.

We searched reviews and meta-analyses on the following databases for the period 1960-2016: the Database of Abstracts of Reviews of Effects (DARE), the Cochrane Database of Systematic Reviews (CDSR) and PubMed. For the DARE and the CDSR databases we searched 
combinations of the following terms: "probiotic", "antibiotic", "diarrhea" and "antibiotic-associated diarrhea". The search yielded 25 results from the DARE and 50 from the CDSR. In PubMed, we searched for meta-analyses using the following search texts: "(probiotic[Title/Abstract] OR probiotics[Title/Abstract]) AND (antibiotic associated diarrhea[Title/Abstract] OR antibiotic-associated diarrhea[Title/Abstract] OR antibiotic associated diarrhoea[Title/Abstract] OR antibiotic-associated diarrhoea[Title/Abstract]))", which yielded 28 results; and "((diarrhea[Title/Abstract] OR diarrhoea[Title/Abstract]) AND (probiotic[Title/Abstract] OR probiotics[Title/Abstract]) AND (antibiotic[Title/Abstract] OR antibiotics[Title/Abstract]))", which yielded 34 results. After screening of titles and abstracts and exclusion of duplicates and reviews not relevant to our purpose, we identified 28 relevant reviews and meta-analyses [13, 27-53], containing a total of 102 relevant studies.

To confirm and update the information obtained from previously published reviews, we also directly searched clinical trials on the Cochrane Central Register of Controlled Trials (CENTRAL), PUBMED and Excerpta Medica Database (EMBASE) for the period 2010-2017. We used the following search texts: "probiotic AND antibiotic associated diarrhea OR antibiotic associated diarrhoea" and "probiotic AND antibiotic AND diarrhea". These searches yielded 26 studies.

Among the studies resulting from our searches, we defined the relevant ones on the basis of specific inclusion criteria: (i) randomized trial, with a double-blind setup and including a placebo control, (ii) clear definition of $\mathrm{AAD}$, and incidence of AAD measured as one of the outcomes, and (iii) probiotic administered for at least the duration of antibiotic therapy. Studies that did not meet the above inclusion criteria were excluded. Furthermore, we excluded studies when diarrhea was already present at the start of the intervention and when the probiotics were tested in combination with other products. We also excluded studies not written in English, studies that were not published or not available, and duplicates (studies reporting results already included in another publication). One author screened the abstract and the body of the papers and extracted information relevant to establish eligibility and conduct the meta-analysis. When the full text of a publication was not accessible, relevant information was obtained from previous reviews. The study was only included when the information available from the other sources met the inclusion criteria.

\section{Data analysis}

For each of the included trials, we calculated the relative risk (RR) and the 95\% confidence interval (CI) for the incidence of diarrhea in the probiotic versus placebo treatment. In addition, we conducted a subgroup analysis by pooling studies based on the composition of the probiotic Microsoft Excel (2016); the Meta-Essentials tool was used to measure heterogeneity and risk of bias [54].

\section{Available probiotic products in the Netherlands}

A complete list of probiotic products available in The Netherlands was obtained in December 2016 by screening online websites of pharmacies, vitamin stores, health stores, and shops selling probiotics online. The Dutch association Natuur- en Gezondheidsproducten Nederland (NPN, Amersfoort, The Netherlands) evaluated and completed our list. We also included dairy products routinely sold in food stores.

\section{Recommendations}

Based on the effectiveness of probiotic strains included in this review in preventing AAD and on the number of studies supporting it, we defined three categories of recommendations. The categories include (i) a three-star recommendation for significant effects for the reduction of AAD shown in at least three of our selected studies, (ii) a two-star recommendation for effects shown in at least two of our selected studies, and (iii) a one-star recommendation for an effect shown in only one study, a trend supported by two or more studies, or the presence of a strain that satisfies one of the above criteria (showing an effect in one study or a trend in at least 2 studies) in sufficient amounts in food supplement or dairy product with a mixed formulation. We screened the list of products available in the Netherlands and selected products that satisfied the criteria above and that contained the relevant strain(s) at a daily dose at least equal to the lowest dose showing an effect in the included studies. For dairy products, we only recommended those that had been specifically included in a clinical trial.

\section{Results}

\section{Search strategy and study selection}

The flow of the meta-analysis, from search to study selection, is depicted in Fig. 2. The literature search identified 128 relevant studies. An overview of these studies, including the reasons for their exclusion, is presented in Additional file 2. A total of 32 trials satisfied our inclusion criteria and were included in the meta-analysis: 26 were obtained from previous reviews [55-80] and six from direct database searches [81-86]. The specific characteristics of all included studies are summarized in Additional file 3.

Most of the studies that were identified through our search, but were excluded from the meta-analysis, did not include a placebo (31\%). The second largest fraction 


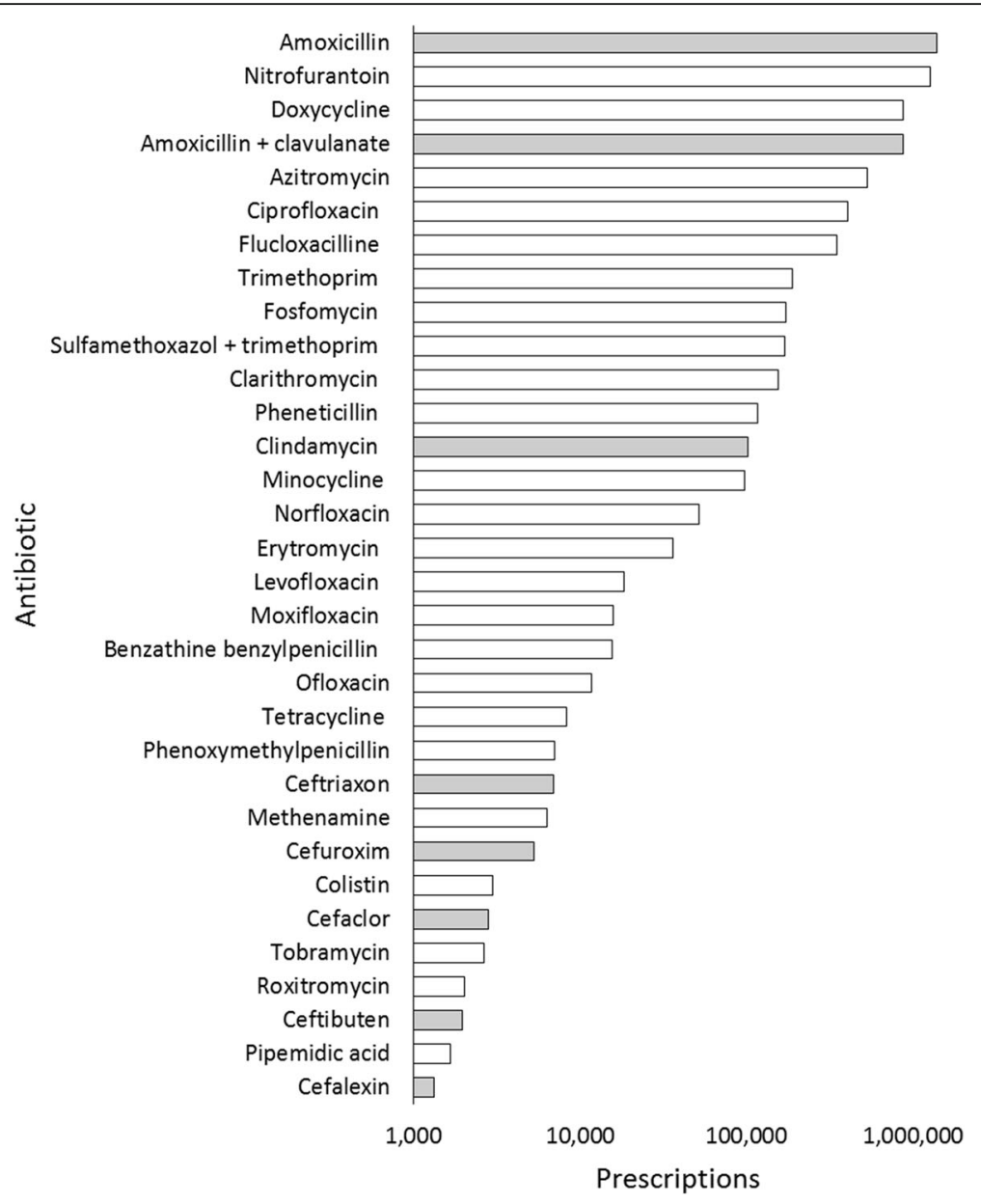

Fig. 1 Prescriptions of antibiotics in The Netherlands including those for high risk of AAD. The data have been extracted from the Genees- en hulpmiddelen Informatie Project (GIP; https://www.gipdatabank.nl/databank) from the Zorginstituut Nederland, that collects trends on use of medication in the Netherlands as reported by health insurance companies. Grey bars indicate the antibiotics that are associated with a higher risk of AAD [11, 14-16]

of excluded studies consisted of studies without a clear definition of AAD (20\%). Among other reasons for exclusion were the lack of a precise measurement of diarrhea, and an unclear duration of the probiotic treatment.

From the total of 32 included studies, five (15.6\%) did not specify the antibiotic used in the trial. Six studies (9\%) used only one antibiotic or combination of antibiotics: two studies used amoxicillin, one used amoxicillin with clavulanic acid, one used a non-specified beta-lactam antibiotic, and two used a combination of three different antibiotics to eradicate Helicobacter pylori infection. The remaining 21 studies $(60 \%)$ enrolled patients that were taking different antibiotics. All of these studies included antibiotics associated with a high risk of AAD, including amoxicillin, beta-lactams, broad-spectrum penicillins, cephalosporins and clindamycin. Ten studies focused on children up to 17 years old (of which one focused on infants 6-36 months), and 22 on adults (three of which focused on elderly over 65 years old).

\section{Data analysis}

The results of the meta-analysis have been summarized in Fig. 3. In this forest plot, studies are pooled based on probiotic formulation and sub-grouped in two categories: dairy products (7 studies) and food supplements (i.e. non-dairy products, 25 studies). Results are also reported for each individual trial in chronological order of publication date in Additional file 4. Overall, probiotics were associated with lower incidence of antibiotic-associated diarrhea $(467 / 3720$ [13\%]) compared to the control (648/3640 [18\%]) (RR 0.66, 95\% CI 0.64-0.67). For trials using probiotic dairy products, the incidence of AAD in the probiotic group was $15.2 \%$ compared to $27.5 \%$ in the control group (RR 1.01, 95\% CI 0.95-1.07). For trials including food supplements (i.e. non-dairy products) the incidence of diarrhea in the probiotic group was $12.2 \%$ 


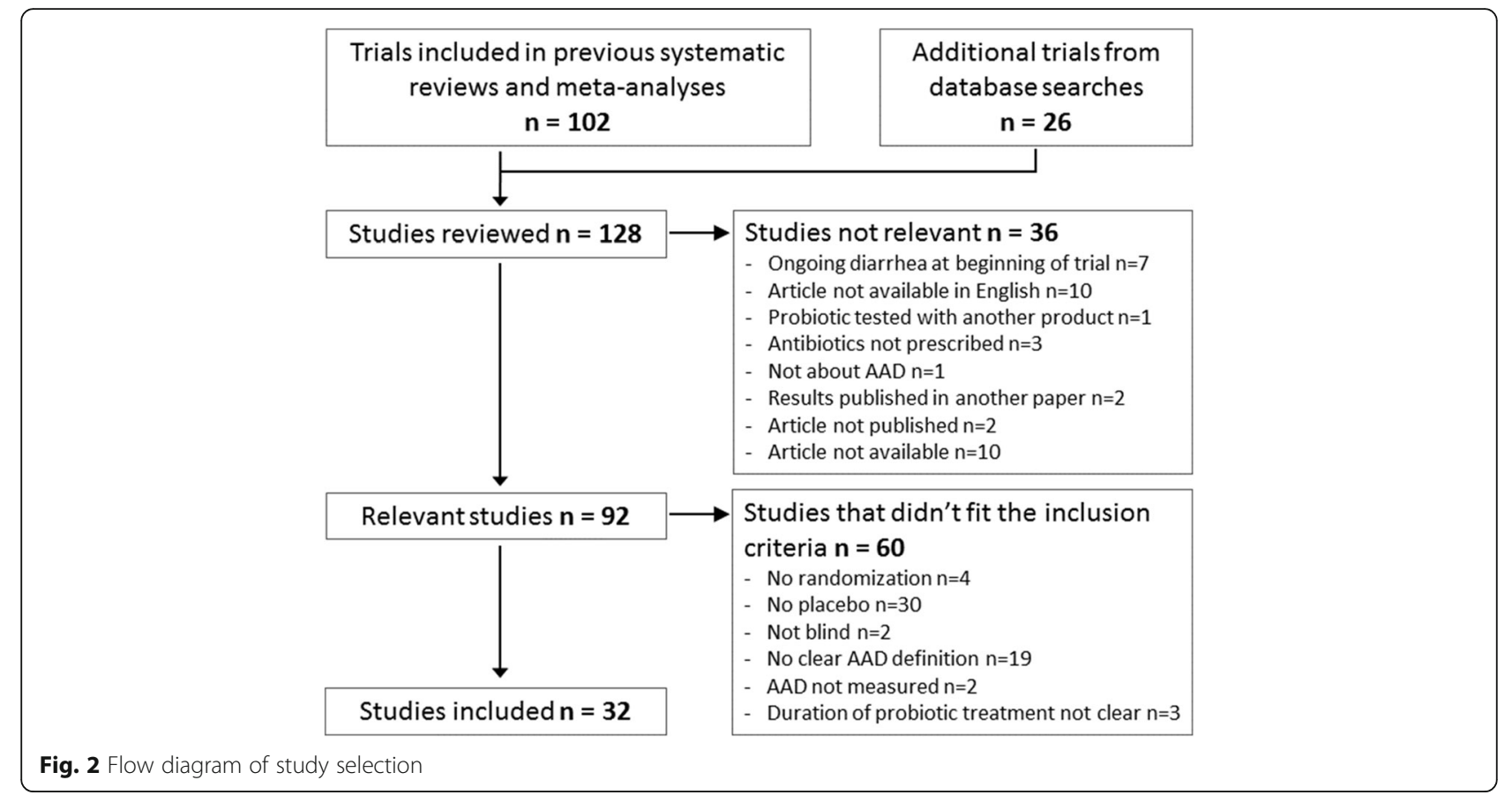

compared to $16.3 \%$ in the control group (RR $0.64,95 \%$ CI 0.63-0.65).

\section{Recommendations}

A compiled list of probiotics available in The Netherlands in December 2016 is presented in Additional file 5. We identified the following strains satisfying the recommendation criteria: Lactobacillus rhamnosus GG with a minimal daily dose of $2 \times 10^{9}$ CFU, to which we assigned a three-star recommendation, as it is associated with a significant reduction in the incidence of AAD in at least three of our selected studies[55, 76, 79]. In addition, the multi-strain formulation of Lactobacillus rhamnosus GG, Lactobacillus acidophilus LA-5, Bifidobacterium lactis BB-12 shows a significant effect in the reduction of AAD in two of our selected studies, but we did not identify an available probiotic product containing this formulation (see further below) [59, 80]. A number of multi-strain formulations led to a one-star recommendation, including those significantly reducing the incidence of AAD in only one selected study: Streptococcus thermophilus and Bifidobacterium lactis (minimal daily dose: 5 billion CFU) [58], Lactobacillus rhamnosus strains Pen, E/N, Oxy (min daily dose: 4 billion CFU) [71] and Lactobacillus acidophilus CL1285, Lactobacillus casei (minimal daily dose: 50 billion CFU) [60]. Furthermore, we assigned a one-star recommendation to formulations that showed a trend supported by two or more studies, including Saccharomyces boulardii (minimal daily dose: 10 billion CFU) [65, 66, 68, 70, 75] and Bifidobacterium bifidum, Bifidobacterium lactis, Enterococcus faecium, Lactobacillus acidophilus, Lactobacillus paracasei, Lactobacillus plantarum, Lactobacillus rhamnosus, Lactobacillus salivarium (minimal daily dose: 10 billion CFU) [63, 64].

We then identified probiotic products (both food supplements and dairy products) to recommend based on the categories above. We recommend food supplements and dairy products that showed a significant effect favoring the probiotic in at least three independent clinical trials in our meta-analysis. No dairy product showed a significant effect for the reduction of the incidence of AAD in at least three clinical studies, and the only food supplement that shows such an effect in at least three clinical studies is Lactobacillus rhamnosus LGG (minimal daily dose: 2 billion CFU) [46, 55, 79]. If we consider the products available in the Netherlands, the recommended products are the food supplements Microbiol Platinum (Vitals) and Culturelle (Allergy Research Group) containing Lactobacillus rhamnosus GG at a daily dose of 33 and 10 billion CFU, respectively (Table 1). We did not identify any dairy products of food supplements products in our two-star category. For the one star category we identified one dairy product and five food supplements containing either the exact (combination of) probiotic(s) that showed a significant effect against $\mathrm{AAD}$ in one clinical trial or a trend in at least two clinical trials, or combinations of different probiotic bacteria, for some of which this effect or trend was proven. We only list and recommend products for which 


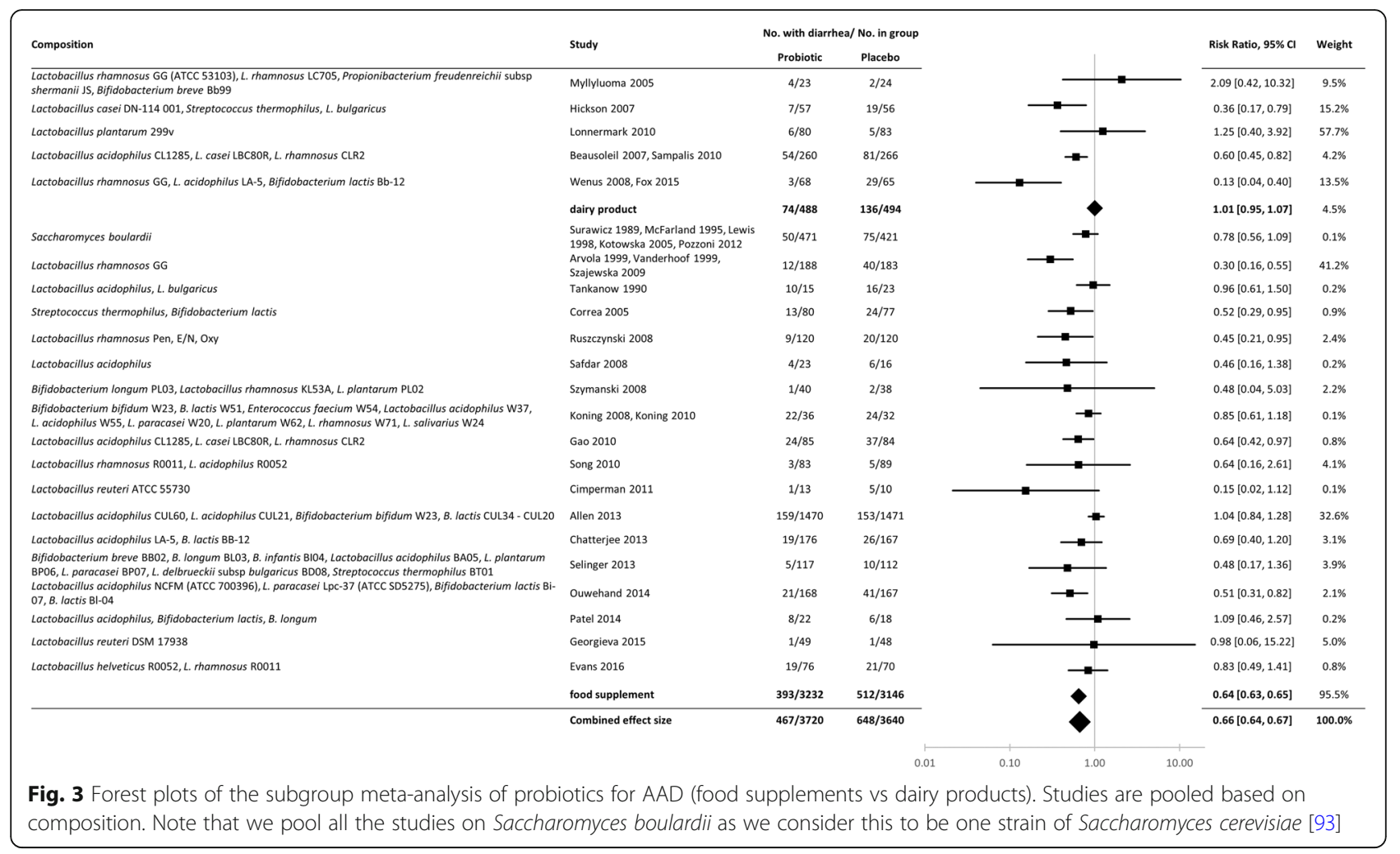

the probiotic strain(s) and CFU-counts are specified and correspond to the strain and dose showing an effect or trend favoring the treatment in the included studies. The one-star dairy products is Actimel (Danone) (daily dose of 20 billion CFU) [62] and the food supplements include Probioticum (Wapiti), Winbiotic Pro-AD (Winclove), Probactiol Duo (Metagenics), Advanced Multi-Billion Dophilus (Solgar), and Imutis (Trenker), as listed in Table 1.

\section{Discussion}

\section{Study selection and inclusion criteria}

In this review we chose to only include studies that had a clear definition of antibiotic-associated diarrhea, to be able to compare their results in a systematic way. However, studies lacking a precise definition of diarrhea may still provide valuable information, and it could be a subject for future discussions how to interpret them and whether to take them into account when formulating recommendations. Furthermore, the strict definition of diarrhea used in some studies means that the protective effect of probiotics against AAD may have been underestimated [67]. Given the scope of the review, we searched for clinical trials involving the use of antibiotics, but we didn't apply strict inclusion criteria regarding the kind of antibiotic used. We didn't look for studies using specific treatments, nor did we exclude studies that did not indicate which antibiotics they used, since diarrhea can be a side-effect of many. Five of the studies that we included did not specify which antibiotic was administered to the patients during the clinical trial. Of the remaining 27 studies, 21 enrolled patients taking different antibiotics, including antibiotic such as broad-spectrum penicillins and cephalosporins associated with a high-risk of AAD.

Only some studies reported which antibiotics were used among the characteristic of patients following treatment [58, 65, 71]. Kotowska et al. [65] suggested that the probiotic they tested (Saccharomyces boulardii) may be effective in preventing diarrhea caused by amoxicillin with clavulanate and by intravenous ceforuxime, but they also mentioned that they could not make definitive conclusions regarding differences in the probiotic's efficacy against different classes of antibiotics. Similarly, other studies could not detect significant differences in this regard, either because of a small sample size (relative to the number of antibiotics tested) or because of the low incidence of diarrhea in the study, or both $[75,82]$. Twenty-two of the studies included in this review included a power analysis. Of these, 11 detected a significant difference between treatment and placebo, including two studies that were underpowered according to their power analysis $[56,65]$. Of the 11 studies that did not detect a significant difference between the treatment and the placebo, four were underpowered [72-74, 85]. By ensuring that clinical trials have enough power it would be possible to identify which probiotics 
Table 1 List of recommended probiotic products

\begin{tabular}{|c|c|c|c|c|c|}
\hline Category & Brand name & Manufacturer & Probiotic strain & CFU per dose & Total daily dose \\
\hline Three-star & Microbiol Platinum & Vitals & Lactobacillus rhamnosus GG & $3.3 \times 10^{10}$ & 1 capsule \\
\hline Three-star & Culturelle & Allergy Research Group & Lactobacillus rhamnosus GG & $1.0 \times 10^{10}$ & 1 capsule \\
\hline One-star & Actimel (dairy product) & Danone & Lactobacillus casei DN-114001 & $1.0 \times 10^{10}$ & 1 bottle $(100 \mathrm{ml})$ \\
\hline One-star & Probioticum & Wapiti & Saccharomyces boulardii & $2.5 \times 10^{9}$ & $1-4$ capsules \\
\hline \multirow[t]{9}{*}{ One-star } & \multirow[t]{9}{*}{ Winbiotic Pro-AD } & \multirow[t]{9}{*}{ Winclove } & Bifidobacterium bifidum W23 & $1.1 \times 10^{9}$ & \multirow[t]{9}{*}{2 sachets } \\
\hline & & & Bifidobacterium lactis W51 & $1.1 \times 10^{9}$ & \\
\hline & & & Enterococcus faecium W54 & $1.1 \times 10^{9}$ & \\
\hline & & & Lactobacillus acidophilus W37 & $1.1 \times 10^{9}$ & \\
\hline & & & Lactobacillus acidophilus W55 & $1.1 \times 10^{9}$ & \\
\hline & & & Lactobacillus paracasei W20 & $1.1 \times 10^{9}$ & \\
\hline & & & Lactobacillus plantarum W62 & $1.1 \times 10^{9}$ & \\
\hline & & & Lactobacillus rhamnosus W71 & $1.1 \times 10^{9}$ & \\
\hline & & & Lactobacillus salivarius W24 & $1.1 \times 10^{9}$ & \\
\hline \multirow[t]{5}{*}{ One-star } & \multirow[t]{5}{*}{ Probactiol Duo } & \multirow[t]{5}{*}{ Metagenics } & Saccharomyces boulardii & $6.0 \times 10^{9}$ & \multirow[t]{5}{*}{$1-2$ capsules } \\
\hline & & & Lactobacillus acidophilus NCFM & $2.1 \times 10^{9}$ & \\
\hline & & & Lactobacillus paracasei Lpc-37 & $2.1 \times 10^{9}$ & \\
\hline & & & Bifidobacterium lactis Bi-04 & $2.1 \times 10^{9}$ & \\
\hline & & & Bifidobacterium lactis Bi-07 & $2.1 \times 10^{9}$ & \\
\hline \multirow[t]{4}{*}{ One-star } & \multirow[t]{4}{*}{ Imutis } & \multirow[t]{4}{*}{ Trenker } & Saccharomyces boulardii & $6.0 \times 10^{9}$ & \multirow[t]{4}{*}{$1-4$ capsules } \\
\hline & & & Lactobacillus acidophilus & $2.0 \times 10^{9}$ & \\
\hline & & & Lactobacillus rhamnosus & $3.0 \times 10^{9}$ & \\
\hline & & & Bifidobacterium longum & $2.0 \times 10^{9}$ & \\
\hline \multirow[t]{4}{*}{ One-star } & \multirow[t]{4}{*}{ Advanced Multi-Billion Dophilus } & \multirow[t]{4}{*}{ Solgar } & Lactobacillus acidophilus LA-5 & $1.3 \times 10^{9}$ & \multirow[t]{4}{*}{1 capsule } \\
\hline & & & Lactobacillus paracasei L CASEl 431 & $1.3 \times 10^{9}$ & \\
\hline & & & Lactobacillus rhamnosus GG & $1.3 \times 10^{9}$ & \\
\hline & & & Bifidobacterium lactis BB-12 & $1.3 \times 10^{9}$ & \\
\hline
\end{tabular}

are most effective in preventing diarrhea caused by specific antibiotics, and clinicians would be able to recommend different probiotic products based on the antibiotic therapy prescribed to their patients.

An important aspect in the design of clinical trials is the inclusion of a placebo control group. This kind of control allows clinicians to account for the placebo effect, which is a well-recognized phenomenon in clinical practice. In clinical trials with dairy products the placebo would ideally consist of a specifically developed product with organoleptic properties very similar to the dairy product containing the probiotics. However, in case of the clinical trials testing probiotic dairy drinks included in this review, the placebo is often a different product. Since we are not aware to which extent these product differences affect the placebo response in individual patients, it may be opportune for producers of probiotic dairy drinks to develop products that can be administered as more appropriate placebos in clinical trials.

\section{Criteria for recommendations}

In this review, we adopted strict criteria to derive recommendations from the results of our meta-analysis. Specifically, we decided to limit strong recommendations for commercial products for which the specific probiotic combination was tested, and not the single species separately, and for which the efficacy of the composition is supported by at least three clinical trials. This approach, although necessary to ensure evidence-based decision making, is limiting, since there are likely other products on the market whose exact composition has not been tested but that may be effective in preventing AAD. In fact, many of the works that we reviewed that assessed the efficacy of multi-strain probiotics (more than three strains) in reducing the risk of AAD, concluded that these products had a significant effect on risk reduction $[63,64,86]$.

For dairy products, we recommended those that were shown to have a positive effect in a clinical trial, but it is possible that products from other brands, with a similar 
formulation, may be as effective as those tested. For example, we reviewed here a study showing a positive effect of the probiotic dairy drink Actimel (Danone) in preventing diarrhea caused by antibiotics [62], and we subsequently included this product in the list of one-star recommendations. The brand Yakult produces a dairy drink containing a strain of Lactobacillus casei that has been shown to be virtually identical to the strain used by the brand Actimel [87], providing an argument for a one-star recommendation to the Yakult dairy drink without the need to conduct additional clinical trials.

Although our recommendations are based on different criteria and are not limited to children, they are in line with those of the European Society for Pediatric Gastroenterology, Hepatology and Nutrition (ESPGHAN) working group [53]. The strain L. rhamnosus GG, for which we make a three-star recommendation, was also strongly recommended for the prevention of AAD in children by the ESPGHAN working group, on the basis of a moderate quality of evidence. The working group also gave a strong recommendation to $S$. boulardii. However, we could not do the same on the basis of our analysis, because we pooled results of patients of different ages. In the forest plot in Additional file 4, S. boulardii shows a positive effect in the prevention of AAD in children [65], a positive trend in adults [68,75], but no positive effect in elderly $[66,70]$. Age is one of the factors that should be taken into account when evaluating health benefits of probiotics. In general, differences in the inclusion criteria, in the methods used to conduct the meta-analysis and in the criteria used to formulate recommendations will result in different evidence-based advice.

\section{Factors affecting the efficacy of probiotics}

Multiple factors can determine the efficacy of probiotic products in specific therapeutic contexts. Firstly, the efficacy of a product can be influenced by its strain composition. One of the most studied probiotic strains is Lactobacillus rhamnosus GG, which has been repeatedly proven effective in reducing in the incidence of diarrhea in antibiotic-treated patients and in treating other gastrointestinal disorders [88]. Different strains of $L$. rhamnosus may not be equally effective in preventing the incidence of side effects of antibiotics [13], and the same is true for other probiotic species. Clinical trials should always specify which probiotic strain they tested, however this is not always the case, making it difficult to evaluate and compare their results. Furthermore, genetic variability has been observed among "identical" strains of LGG [89], so even when studies indicate precisely which strain they used it is not possible to exclude the possibility of within-strain differences affecting the results of the trial. Apart from strain composition, the formulation of a probiotic product (specific combination of strains) may affect its efficacy. This effect may be particularly significant in dairy products, since the quality of the product will vary depending on the specific strains used during the fermentation, and whether they are included during the process or added as ingredients to the final product. In this review we have analyzed dairy products and food supplements separately, and we have only combined probiotic products with the exact same strain composition and formulation, in order to minimize the effect of these factors on the results of the meta-analysis.

Apart from strain composition and probiotic product formulation, specific individual differences (age, specific health condition, genetic factors and differences in the composition of the gut microbiome) might play a role in the efficacy of probiotics, as is evident in some of the trials we reviewed.

The largest study included in this review contained almost 3000 subjects, as reported by Allen [81]. This study showed no significant effect of probiotic versus placebo. However, it included elderly participants (over 65) who may be more susceptible to adverse effects of antibiotics.. The efficacy of probiotics varies across different age groups, and is influenced by the type of antibiotic administered and the duration of the therapy. In fact, higher incidence rates of AAD were previously observed in older patients also subjected to prolonged antibiotic exposure [84], so the same factors may partly explain the observation of the study by Allen. Furthermore, in the study by Allen antibiotic therapy could last up to 7 days before starting the probiotic treatment, and probiotics may be more effective when administered during the entire period of susceptibility. In fact, a meta-regression analysis conducted by Shen et al. [90] showed that probiotics were significantly more effective in reducing the risk of Clostridium difficile infection when administered closer to the first antibiotic dose, and similar considerations could be applied to the use of probiotics to prevent $A A D$.

The efficacy of probiotics in preventing AAD also depends on the dose. A daily intake of at least $5 \times 10^{9}$ CFU is associated with significant efficacy for AAD [41, 91], and it has been shown that higher probiotic dose is linked to greater efficacy [60, 84]. Although only few dose-effect studies have been performed, they observe a positive correlation between dose and AAD risk [92].

Since so many factors can affect the efficacy of probiotics in prophylaxis, researchers should be rigorous in setting up clinical trials and in providing as much information as possible about them. Studies should report characteristics of the probiotic (strain, dose and duration of therapy), of the antibiotic (type of antibiotic, duration of the therapy) of the patients (age group, 
diagnosis) and accurate definitions of measured outcomes and adverse effects. In this way, results from different trials can be assessed, compared and used as a basis to formulate recommendations. Individual factors, that are not routinely monitored in clinical trials, may influence the incidence and gravity of side effects and the efficacy of probiotics. For example, each individual has their own unique microbiota, and the impact of a given antibiotic on the composition and stability of different microbial ecosystems can be different; therefore, a specific probiotic strain or combination of strains may not have the same efficacy for every person. Especially for some patients, for example those who are frequently treated with antibiotics such as elderly in care facilities, it is certainly worth being flexible and trying different probiotics until the most effective one has been found. Future research can guide the formulation of personalized therapies.

\section{Conclusion}

We present here a workflow for the assessment of the efficacy of probiotics for the prevention of antibiotic-associated diarrhea. The workflow consists of a series of steps (systematic review of available literature and meta-analysis of relevant clinical trials, inventory of available products and formulation of evidence-based recommendations) that can be applied to other cases, upon adaptation of methodological details such as the inclusion criteria. In order to make strong, evidence-based recommendations it is important that research of high-quality is available, in which adequate methods are followed to perform the trials and to report the results. We conclude that there is sufficient evidence to make a recommendation for the use of specific probiotic products for the prevention of antibiotic associated diarrhea. In particular, we provide a three-star recommendation for preparations with a minimal daily dose of $2 \times 10^{9} \mathrm{CFU}$ of the probiotic strain Lactobacillus rhamnosus GG.

\section{Additional files}

Additional file 1: Side-effects of antibiotics. List of commonly prescribed antibiotics in The Netherlands, with information on class, mode of action, indication and side effects. (XLSX $29 \mathrm{~kb}$ )

Additional file 2: List of reviewed studies. All the clinical trials that were reviewed are listed with indication of first author, publication title, publication date, whether they were included in the review, and, in case, reasons for exclusion. (XLSX $26 \mathrm{~kb}$ )

Additional file 3: Characteristics of included studies. For every study included in this review, information on study population (number of patients enrolled, age, setting, country, diagnosis and antibiotics prescribed), probiotic treatment (composition, daily dose, intake form, brand, duration of treatment) and outcome (definition of AAD, incidence in probiotic and placebo groups, significance of difference, relative risk) is summarized. (XLSX $39 \mathrm{~kb})$
Additional file 4: Probiotics for prevention of antibiotic-associated diarrhea (AAD) in 32 randomized, double-blind, placebo-controlled trials. Forest plot summarizing the results of the meta-analysis for all the clinical trials included in this review, listed in chronological order of publication date. (PNG 83 kb)

Additional file 5: Probiotic products available in The Netherlands. List of probiotic products available in the Netherlands, with information on composition (strains), dosage form, and number of colony-forming units (CFU) per daily dose. (XLSX 54 kb)

\section{Abbreviations}

AAD: Antibiotic-associated diarrhea; AHRQ: Agency for Healthcare Research and Quality; CDSR: Cochrane Database of Systematic Reviews; CENTRAL: Cochrane Central Register of Controlled Trials; CFU: Colonyforming units; Cl: Confidence interval; DARE: Database of Abstracts of Reviews of Effects; EMBASE: Excerpta Medica Database; ESPGHAN: European Society for Pediatric Gastroenterology, Hepatology and Nutrition; NPN: Natuur-en Gezondheidsproducten Nederland; RCT: Randomized controlled trial; RR: Relative risk

\section{Acknowledgements}

The authors thank Prof. Dr. Michiel Kleerebezem (Wageningen University and Research Centre, Host-Microbe Interactomics group) for critically reading the manuscript. We acknowledge Eveline Hensel, Jasper Buikx, Janna Laeven and Haig Balian from ARTIS-Micropia for their contributions to this Dutch guide for probiotics.

\section{Funding}

The study was funded by the Netherlands Organization for Applied Scientific Research (TNO, Zeist, The Netherlands) and ARTIS-Micropia, the microbe museum in Amsterdam, The Netherlands. VA and RK are employed by TNO. RK holds a position as the ARTIS-Micropia professor at the VU University Amsterdam

\section{Availability of data and materials}

All the data supporting the conclusions of this article are included within the published article and its Additional files.

\section{Authors' contributions}

VA carried out the meta-analysis, wrote the paper and made the figs. CK, GK and RK contributed to the text of the manuscript. All authors contributed to stimulating discussions with healthcare professionals (including those at the launch of the guide at ARTIS-Micropia, Amsterdam), which fueled the content of the manuscript. RK initiated and coordinated the study. All authors critically read, corrected and approved the final manuscript.

Ethics approval and consent to participate

Not applicable.

\section{Consent for publication}

Not applicable.

\section{Competing interests}

RK is co-founder of the Yoba for Life foundation (2009), a non-profit organization, accredited by the Dutch Tax Authorities as a Public Benevolent Institution (PBI), which aims to promote local production and consumption of fermented products in Africa. African fermented products made with the Yoba starter culture, are not marketed by the foundation as such, but the Yoba for Life foundation stimulates local production and ownership, allowing income-generating activities for African small-scale entrepreneurs in the food sector. The Yoba for Life foundation distributes and sells ready-to-use sachets with dried bacterial starter cultures through a network of partners and volunteers to facilitate the local production of dairy and cereal-based products by controlled bacterial fermentation. The Yoba starter culture contains Lactobacillus rhamnosus yoba 2012, which is a generic variant of Lactobacillus rhamnosus GG. VA, CK and GR declare no competing interests.

\section{Publisher's Note}

Springer Nature remains neutral with regard to jurisdictional claims in published maps and institutional affiliations. 


\section{Author details}

${ }^{1}$ Microbiology and Systems Biology, Netherlands Organization for Applied Scientific Research (TNO), Utrechtseweg 48, 3704, HE, Zeist, The Netherlands. ${ }^{2}$ University College Roosevelt, Lange Noordstraat 1, 4331, CB, Middelburg, The Netherlands. ${ }^{3}$ Artis-Micropia, Plantage Kerklaan 38, 1018, CZ, Amsterdam, The Netherlands. ${ }^{4}$ Department of Molecular Cell Biology, VU University Amsterdam, De Boelelaan 1085, 1081, HV, Amsterdam, The Netherlands.

\section{Received: 28 August 2017 Accepted: 21 June 2018}

Published online: 06 August 2018

\section{References}

1. Keeney KM, Yurist-Doutsch S, Arrieta M-C, Finlay BB. Effects of antibiotics on human microbiota and subsequent disease. Annu. Rev. Microbiol. 2014;68: 217-35.

2. Francino MP. Antibiotics and the human gut microbiome: Dysbioses and accumulation of resistances. Front. Microbiol. 2016;6:1-11.

3. Sarker P, Mily A, Mamun A, Jalal S, Bergman P, Raqib R, et al. Ciprofloxacin affects host cells by suppressing expression of the endogenous antimicrobial peptides cathelicidins and beta-defensin-3 in colon epithelia. Antibiotics. 2014;3:353-74.

4. Croswell A, Amir E, Teggatz P, Barman M, Salzman NH. Prolonged impact of antibiotics on intestinal microbial ecology and susceptibility to enteric Salmonella infection. Infect. Immun. 2009;77:2741-53.

5. Jernberg C, Löfmark S, Edlund C, Jansson JK. Long-term ecological impacts of antibiotic administration on the human intestinal microbiota. ISME J. 2007;1:56-66.

6. Turck D, Bernet J-P, Marx J, Kempf H, Giard P, Walbaum O, et al. Incidence and risk factors of oral antibiotic-associated diarrhea in an outpatient pediatric population. J. Pediatr. Gastroenterol. Nutr. 2003;37:22-6.

7. Wiström J, Norrby SR, Myhre EB, Eriksson S, Granström G, Lagergren L, et al. Frequency of antibiotic-associated diarrhoea in 2462 antibiotic-treated hospitalized patients: a prospective study. J. Antimicrob. Chemother. 2001; 47:43-50.

8. Kramer MS, Hutchinson TA, Naimark L, Contardi R, Flegel KM, Leduc DG Antibiotic-associated gastrointestinal symptoms in general pediatric outpatients. Pediatrics. 1985;76:365-70.

9. Kuyvenhoven MM, van Balen FAM, Verheij TJM. Outpatient antibiotic prescriptions from 1992 to 2001 in The Netherlands. J. Antimicrob. Chemother. 2003;52:675-8.

10. GIP/Zorglnstituut Nederland [Internet]. 2016. Available from: https://www. gipdatabank.nl/databank. Accessed Feb 2017.

11. Joint FAO/WHO expert consultation. Health and nutrition properties of probiotics in food including powder milk with live lactic acid bacteria. 2001.

12. Hill C, Guarner F, Reid G, Gibson GR, Merenstein DJ, Pot B, et al. Expert consensus document: The international scientific association for probiotics and prebiotics consensus statement on the scope and appropriate use of the term probiotic. Nat. Rev. Gastroenterol. Hepatol. 2014;11:506-14.

13. Ritchie ML. Romanuk TN. A meta-analysis of probiotic efficacy for gastrointestinal diseases. PLoS One. 2012;7:e34938

14. Lee YK, Puong KY, Ouwehand AC, Salminen S. Displacement of bacterial pathogens from mucus and Caco-2 cell surface by lactobacilli. J. Med. Microbiol. 2003;52:925-30.

15. Von Ossowski I, Reunanen J, Satokari R, Vesterlund S, Kankainen M, Huhtinen $\mathrm{H}$, et al. Mucosal adhesion properties of the probiotic Lactobacillus rhamnosus GG SpaCBA and SpaFED pilin subunits. Appl. Environ. Microbiol. 2010;76:2049-57

16. Collado MC, González A, González R, Hernández M, Ferrús MA, Sanz Y. Antimicrobial peptides are among the antagonistic metabolites produced by Bifidobacterium against Helicobacter pylori. Int. J. Antimicrob. Agents. 2005;25:385-91.

17. Chu W, Lu F, Zhu W, Kang C. Isolation and characterization of new potential probiotic bacteria based on quorum-sensing system. J. Appl. Microbiol. 2011;110:202-8

18. Cotter PD, Hill C, Ross PR, Paul D, Cotter CH, Bacteriocins RPR. developing innate immunity for food. Nat. Rev. Microbiol. 2005;3:777-88.

19. Servin AL. Antagonistic activities of lactobacilli and bifidobacteria against microbial pathogens. FEMS Microbiol. Rev. 2004;28:405-40.

20. Ashraf R, Shah NP. Immune system stimulation by probiotic microorganisms. Crit. Rev. Food Sci. Nutr. 2014;54:938-56.
21. Hempel S, Newberry S, Ruelaz A, Wang Z, Miles JN V, Suttorp MJ, et al. Safety of probiotics used to reduce risk and prevent or treat disease. Evid Rep Technol Assess. 2011;200:1-645.

22. Snydman DR. The safety of probiotics. Clin. Infect. Dis. 2008:46:S104-11.

23. Stadlbauer V. Immunosuppression and probiotics: Are they effective and safe? Benef. Microbes. 2015;6:823-8.

24. Didari T, Solki S, Mozaffari S, Nikfar S, Abdollahi M. A systematic review of the safety of probiotics. Expert Opin. Drug Saf. 2014;13:227-39.

25. Sharma P, Tomar SK, Goswami P, Sangwan V, Singh R. Antibiotic resistance among commercially available probiotics. Food Res. Int. 2014;57:176-95.

26. Wong A, Ngu DY, Dan LA, Ooi A, Lim RL. Detection of antibiotic resistance in probiotics of dietary supplements. Nutr J. 2015;14:95.

27. Avadhani A, Miley H. Probiotics for prevention of antibiotic-associated diarrhea and Clostridium difficile-associated disease in hospitalized adults - A meta-analysis. J. Am. Acad. Nurse Pract. 2011:23:269-74.

28. Butler CC, Duncan D, Hood K. Does taking probiotics routinely with antibiotics prevent antibiotic associated diarrhoea? BMJ. 2012;344:e682.

29. Cremonini F, Di Caro S, Nista EC, Bartolozzi F, Capelli G, Gasbarrini G, et al. Meta-analysis: the effect of probiotic administration on antibiotic-associated diarrhoea. Aliment. Pharmacol. Ther. 2002;16:1461-7.

30. Dendukuri N, Costa V, McGregor M, Brophy JM. Probiotic therapy for the prevention and treatment of Clostridium difficile-associated diarrhea: a systematic review. Can. Med. Assoc. J. 2005;173:167-70.

31. D'Souza AL, Rajkumar C, Cooke J, Bulpitt CJ. Probiotics in prevention of antibiotic associated diarrhoea: meta-analysis. BMJ. 2002;324:1-6.

32. Goldenberg J, Lytvyn L, Steurich J, Parkin P, Mahant S, Johnston B. Probiotics for the prevention of pediatric antibiotic-associated diarrhea. Cochcrane Database Syst. Rev. 2015;(12):CD004827.

33. Goldenberg J, Ma S, Saxton J, Martzen M, Vandvik P, Thorlund K, et al. Probiotics for the prevention of Clostridium difficile- associated diarrhea in adults and children. Cochrane Database Syst. Rev. 2013;(12):CD006095.

34. Hawrelak JA, Whitten DL, Myers SPI. Lactobacillus rhamnosus GG effective in preventing the onset of antibiotic-associated diarrhoea: a systematic review. Digestion. 2005;72:51-6.

35. Hempel S, Newberry SJ, Maher AR, Wang Z, Miles JNV, Shanman R, et al. Probiotics for the prevention and treatment of antibiotic-associated diarrhea. Clin. Corner. 2012;307:1959-69.

36. Johnston BC, Supina AL, Vohra S. Probiotics for pediatric antibioticassociated diarrhea: a meta-analysis of randomized placebo-controlled trials. Can. Med. Assoc. J. 2006:175:377-83.

37. Johnston B, Goldenberg J, Vandvik P, Sun X, Guyatt G. Probiotics for the prevention of pediatric antibiotic-associated diarrhea (Cochrane Review). Cochrane Libr. 2011;(11):CD004827.

38. Johnston BC, Ma SS, Goldenberg JZ, Thorlund K, Vandvik PO, Loeb M, et al. Probiotics for the prevention of Clostridium difficile-associated diarrhea. Ann Intern Med. 2012;157:878-88

39. Kale-Pradhan PB, Jassal HK, Wilhelm SM. Role of Lactobacillus in the prevention of antibiotic-associated diarrhea: a meta-analysis. Pharmacotherapy. 2010;30:119-26.

40. McFarland LV. Probiotics for the primary and secondary prevention of C. difficile infections: A meta-analysis and systematic review. Antibiotics. 2015:4:160-78.

41. McFarland LV. Meta-analysis of probiotics for the prevention of antibiotic associated diarrhea and the treatment of Clostridium difficile disease. Am. J. Gastroenterol. 2006;101:812-22.

42. McFarland LV. Systematic review and meta-analysis of Saccharomyces boulardii in adult patients. World J. Gastroenterol. 2010;16:2202-22.

43. Pattani R, Palda VA, Hwang SW, Shah PS. Probiotics for the prevention of antibiotic-associated diarrhea and Clostridium difficile infection among hospitalized patients: systematic review and meta-analysis. Open Med. 2013;7:e56

44. Pillai A, Nelson RL. Probiotics for treatment of Clostridium difficile-associated colitis in adults. Cochrane Database Syst. Rev. 2008;(1):CD004611.

45. Szajewska H, Meta-analysis MJ. Non-pathogenic yeast Saccharomyces boulardii in the prevention of antibiotic-associated diarrhoea. Aliment. Pharmacol. Ther. 2005;22:365-72.

46. Szajewska H, Kołodziej M. Systematic review with meta-analysis: Lactobacillus rhamnosus GG in the prevention of antibiotic-associated diarrhoea in children and adults. Aliment. Pharmacol. Ther. 2015:42:1149-57.

47. Szajewska H, Kołodziej M. Systematic review with meta-analysis: Saccharomyces boulardii in the prevention of antibiotic-associated diarrhoea. Aliment. Pharmacol. Ther. 2015;42:793-801. 
48. Szajewska H, Ruszczyński M, Radzikowski A. Probiotics in the prevention of antibiotic-associated diarrhea in children: a meta-analysis of randomized controlled trials. J. Pediatr. 2006;149:367-72.

49. Tung JM, Dolovich LR, Lee $\mathrm{CH}$. Prevention of Clostridium difficile infection with Saccharomyces boulardii: a systematic review. Can. J. Gastroenterol. 2009;23:817-21.

50. Urbańska M, Gieruszczak-Białek D, Szajewska H. Systematic review with meta-analysis: Lactobacillus reuteri DSM 17938 for diarrhoeal diseases in children. Aliment. Pharmacol. Ther. 2016;43:1025-34.

51. Videlock EJ, Cremonini F. Meta-analysis: probiotics in antibiotic-associated diarrhoea. Aliment. Pharmacol. Ther. 2012;35:1355-69.

52. Zou J, Dong J, Meta-Analysis YX. Lactobacillus containing quadruple therapy versus standard triple first-line therapy for Helicobacter pylori eradication. Helicobacter. 2009;14:449-59.

53. Szajewska H, Canani RB, Guarino A, Hojsak I, Indrio F, Kolacek S, et al. Probiotics for the prevention of antibiotic-associated diarrhea in children. J. Pediatr. Gastroenterol. Nutr. 2016:62:495-506.

54. Suurmond $R$, van Rhee $H$, Hak T. Introduction, comparison, and validation of Meta-Essentials: A free and simple tool for meta-analysis. Res. Synth. Methods. 2017;8:537-53.

55. Arvola T, Laiho K, Torkkeli S, Mykka H. Children With Respiratory Infections : A Randomized Study. 1999;104

56. Beausoleil M, Fortier N, Guénette $S$, L'Ecuyer $A$, Savoie M, Franco M, et al. Effect of a fermented milk combining Lactobacillus acidophilus CL1285 and Lactobacillus casei in the prevention of antibiotic-associated diarrhea: A randomized, double-blind, placebo-controlled trial. Can. J. Gastroenterol. 2007;21:732-6.

57. Cimperman L, Bayless G, Best K, Diligente A, Mordarski B, Oster M, et al. A randomized, double-blind, placebo-controlled pilot study of Lactobacillus reuteri ATCC 55730 for the prevention of antibiotic-associated diarrhea in hospitalized adults. J. Clin. Gastroenterol. 2011;45:785-9.

58. Correa NB, Peret Filho LA, Penna FJ, Lima FM, Nicoli JR. A randomized formula controlled trial of Bifidobacterium lactis and Streptococcus thermophilus for prevention of antibiotic-associated diarrhea in infants. J. Clin. Gastroenterol. 2005;39:385-9.

59. Fox MJ, Ahuja KDK, Robertson IK, Ball MJ, Eri RD. Can probiotic yogurt prevent diarrhoea in children on antibiotics? A double-blind, randomised, placebo-controlled study. BMJ Open. 2015;5:e006474

60. Gao XW, Mubasher M, Fang CY, Reifer C, Miller LE. Dose-response efficacy of a proprietary probiotic formula of Lactobacillus acidophilus CL1285 and Lactobacillus casei LBC80R for antibiotic-associated diarrhea and Clostridium difficile-associated diarrhea prophylaxis in adult patient. Am. J. Gastroenterol. Nature Publishing Group. 2010;105:1636-41.

61. Georgieva M, Pancheva R, Rasheva N, Usheva N, Ivanova L, Koleva K. Use of the probiotic Lactobacillus reuteri DSM 17938 in the prevention of antibioticassociated infections in hospitalized Bulgarian children: a randomized, controlled trial. J. IMAB - Annu. Proceeding. 2015;21:895-900.

62. Hickson M, D'Souza AL, Muthu N, Rogers TR, Want S, Rajkumar C, et al. Use of probiotic Lactobacillus preparation to prevent diarrhoea associated with antibiotics: randomised double blind placebo controlled trial. BMJ. 2007:335:80

63. Koning CJ, Jonkers D, Smidt H, Rombouts F, Pennings HJ, Wouters E, et al. The effect of a multispecies probiotic on the composition of the faecal microbiota and bowel habits in chronic obstructive pulmonary disease patients treated with antibiotics. Br J Nutr. 2009;103:1452-60.

64. Koning CJM, Jonkers DMAE, Stobberingh EE, Mulder L, Rombouts FM, Stockbrügger RW. The effect of a multispecies probiotic on the intestinal microbiota and bowel movements in healthy volunteers taking the antibiotic amoxycillin. Am. J. Gastroenterol. 2008;103:178-89.

65. Kotowska M, Albrecht P, Szajewska H. Saccharomyces boulardii in the prevention of antibiotic-associated diarrhoea in children: A randomized double-blind placebo-controlled trial. Aliment. Pharmacol. Ther. 2005;21:583-90.

66. Lewis SJ, Potts L, Barry RE. The lack of therapeutic effect of Saccharomyces boulardii in the prevention of antibiotic-related diarrhoea in elderly patients. J. Infect. 1998;36:171-4.

67. Lönnermark E, Friman V, Lappas G, Sandberg T, Berggren A, Adlerberth I. Intake of Lactobacillus plantarum reduces certain gastrointestinal symptoms during treatment with antibiotics. J. Clin. Gastroenterol. 2010;44:106-12.

68. McFarland L, Surawicz C. Prevention of lactam associated diarrhoea by Saccharomyces boulardii compared with placebo. Am J Gastroenterol. 1995; 90:439-48.
69. Myllyluoma E, Veijola L, Ahlroos T, Tynkkynen S, Kankuri E, Vapaatalo H, et al. Probiotic supplementation improves tolerance to Helicobacter pylori eradication therapy - A placebo-controlled, double-blind randomized pilot study. Aliment. Pharmacol. Ther. 2005;21:1263-72.

70. Pozzoni P, Riva A, Bellatorre A, Amigoni M, Redaelli E, Ronchetti A, et al. Saccharomyces boulardii for the prevention of antibiotic-associated diarrhea in adult hospitalized patients: a single-center, randomized, double-blind, placebo-controlled trial. Am. J. Gastroenterol. 2012;107:922-31.

71. Ruszczyński M, Radzikowski A, Szajewska H. Clinical trial: Effectiveness of Lactobacillus rhamnosus (strains E/N, Oxy and Pen) in the prevention of antibiotic-associated diarrhoea in children. Aliment. Pharmacol. Ther. 2008;28:154-61

72. Safdar N, Barigala R, Said A, McKinley L. Feasibility and tolerability of probiotics for prevention of antibiotic-associated diarrhoea in hospitalized US military veterans. J. Clin. Pharm. Ther. 2008;33:663-8.

73. Sampalis J, Psaradellis E, Rampakakis E. Efficacy of BIO K+ CL1285 in the reduction of antibiotic-associated diarrhea - A placebo controlled doubleblind randomized, multi-center study. Arch. Med. Sci. 2010;6:56-64.

74. Song HJ, Kim J-Y, Jung S-A, Kim S-E, Park H-S, Jeong Y, et al. Effect of probiotic Lactobacillus (Lacidofil ${ }^{\circledR}$ cap) for the prevention of antibioticassociated diarrhea: a prospective, randomized, double-blind, multicenter study. J. Korean Med. Sci. 2010;25:1784-91.

75. Surawicz CM, Elmer GW, Speelman P, McFarland L V, Chinn J, Belle VAN. Prevention of antibiotic-associated diarrrhea by Sacchromyces boulardii: A Prospective study. 1989;96:981-88.

76. Szajewska H, Albrecht P, Topczewska-cabanek A. Randomized, double-blind, placebo-controlled trial: Effect of Lactobacillus GG supplementation on Helicobacter pylori eradication rates and side effects during treatment in children. J Pediatr Gastroenterol Nutr. 2009;431-436.

77. Szymański H, Armańska M, Kowalska-Duplaga K, Szajewska H. Bifidobacterium longum PL03, Lactobacillus rhamnosus KL53A, and Lactobacillus plantarum PL02 in the prevention of antibiotic-associated diarrhea in children: A randomized controlled pilot trial. Digestion. 2008;78:13-7.

78. Tankanow RM, Ross MB, Ertel IJ, Dickinson DG, McCormick LS, Garfinkel JF. A double-blind, placebo-controlled study of the efficacy of Lactinex in the prophylaxis of amoxicillin-induced diarrhea. Dicp. 1990;24:382-4.

79. Vanderhoof JA, Whitney DB, Antonson DL, Hanner TL, Lupo JV, Young RJ. Lactobacillus GG in the prevention of antibiotic-associated diarrhea in children. J. Pediatr. 1999;135:564-8.

80. Wenus C, Goll R, Loken EB, Biong AS, Halvorsen DS, Florholmen J. Prevention of antibiotic-associated diarrhoea by a fermented probiotic milk drink. Eur. J. Clin. Nutr. 2008;62:299-301.

81. Allen SJ, Wareham K, Wang D, Bradley C, Hutchings H, Harris W, et al. Lactobacilli and bifidobacteria in the prevention of antibiotic-associated diarrhoea and Clostridium difficile diarrhoea in older inpatients (PLACIDE): a randomised, double-blind, placebo-controlled, multicentre trial. Lancet. 2013:382:1249-57.

82. Chatterjee S, Kar P, Das T, Ray S, Ganguly S, Rajendiran C, et al. Randomized placebo-controlled double blind multicentric trial on efficacy and safety of Lactobacillus acidophilus LA-5 and Bifidobacterium BB-12 for prevention of antibiotic-associated diarrhea. J. Assoc. Physicians India. 2013:61:708-12.

83. Evans M, Salewski RP, Christman MC, Girard S-A, Tompkins TA. Effectiveness of Lactobacillus helveticus and Lactobacillus rhamnosus for the management of antibiotic-associated diarrhoea in healthy adults: a randomised, doubleblind, placebo-controlled trial. Br. J. Nutr. 2016;116:94-103.

84. Ouwehand AC, DongLian C, Weijian X, Stewart M, Ni J, Stewart T, et al. Probiotics reduce symptoms of antibiotic use in a hospital setting: $A$ randomized dose response study. Vaccine. 2014;32:458-63.

85. Patel J, Curry WJ, Graybill MA, Bernard S, Mcdermott AS, Karpa K. Randomized study of probiotics in primary care. J. Pharm. Heal. Serv. Res. 2014:5:187-90.

86. Selinger CP, Bell A, Cairns A, Lockett M, Sebastian S, Haslam N. Probiotic VSL\#3 prevents antibiotic-associated diarrhoea in a double-blind, randomized, placebo-controlled clinical trial. J. Hosp. Infect. 2013;84:159-65.

87. Douillard FP, Kant R, Ritari J, Paulin L, Palva A, De Vos WM. Comparative genome analysis of Lactobacillus casei strains isolated from Actimel and Yakult products reveals marked similarities and points to a common origin. Microb. Biotechnol. 2013;6:576-87.

88. Horvath A, Dziechciarz P, Szajewska H. Meta-analysis: Lactobacillus rhamnosus GG for abdominal pain-related functional gastrointestinal disorders in childhood. Aliment. Pharmacol. Ther. 2011;33:1302-10. 
89. Sybesma W, Molenaar D, Van IJcken W, Venema K, Korta R. Genome instability in Lactobacillus rhamnosus GG. Appl. Environ. Microbiol. 2013;79:2233-2239.

90. Shen NT, Maw A, Tmanova LL, Pino A, Ancy K, Crawford CV, et al. Timely use of probiotics in hospitalized adults prevents Clostridium difficile infection: a systematic review with meta-regression analysis. Gastroenterology. Elsevier, Inc. 2017;152:1889-1900.e9.

91. Hayes SR, Vargas AJ. Probiotics for the prevention of pediatric antibioticassociated diarrhea. Explor. J. Sci. Heal. 2016;12:463-6.

92. Ouwehand AC. A review of dose-responses of probiotics in human studies. Benef. Microbes. 2016:1-10.

93. Edwards-Ingram L, Gitsham P, Burton N, Warhurst G, Clarke I, Hoyle D, et al. Genotypic and physiological characterization of Saccharomyces boulardii, the probiotic strain of Saccharomyces cerevisiae. Appl. Environ. Microbiol. 2007;73:2458-67.

Ready to submit your research? Choose BMC and benefit from:

- fast, convenient online submission

- thorough peer review by experienced researchers in your field

- rapid publication on acceptance

- support for research data, including large and complex data types

- gold Open Access which fosters wider collaboration and increased citations

- maximum visibility for your research: over $100 \mathrm{M}$ website views per year 